\title{
Cognitive Linguistics and Humor Research
}

\section{Introduction}

Over the last three decades, the paths of humor research and Cognitive Linguistics have crossed on a regular basis and in different ways. This can be attributed to a number of reasons, including a shared epistemological basis of the leading linguistic humor theories and Cognitive Linguistics (henceforth $\mathrm{CL}$ ), the central interest of $\mathrm{CL}$ in the cognitive operations driving language (including the classical cases of figurative language), and the inclusion of cognitive linguistic concepts in recent humor-theoretical work. In what follows, we will briefly go into each of these reasons before presenting a more extensive overview of the contribution of $C L$ to humor research.

First of all, since the publication of Semantic Mechanisms of Humor (Raskin 1985), the focus of linguistic humor research has been strongly cognitive, as the Semantic Script Theory of Humor (SSTH), and its further development into the General Theory of Verbal Humor (GTVH, Attardo and Raskin 1991; Attardo 1994, 2001) are deeply rooted in concepts that relate to the foundations of $\mathrm{CL}$. This obviously holds for the notion of semantic scripts, which builds the epistemological basis of the SSTH and refers to cognitive structures representing speakers' knowledge of specific aspects of the world, rooted in experience (Raskin 1985: 81). In that respect, scripts are comparable to the concepts of frames (Fillmore 1982, 1985), conceptual domains (Lakoff and Johnson 1980; Lakoff 1987; Langacker 2008) and Idealized Cognitive Models (ICMs, Lakoff 1987), which figure prominently in a range of cognitive linguistic models of grammar and semantics (including conceptual metaphor theory, mental spaces theory, construction grammar, and Cognitive Grammar). Next to the central notion of scripts, other concepts that have played a substantial role in both Cognitive Linguistics and humor research, are conceptual mappings (Fauconnier 1997, Coulson 2000, Attardo et al. 2002) and the idea of blended structures consisting of input from different scripts/frames/domains (Fauconnier and Turner 1998, 2002; Turner 2014; cf. Koestler's (1964/1989) notion of bisociation as an early adaption of hybrid structures to creative and imaginative cognition, including humor, and 
Hofstadter and Gabora 1989, infra). These and other concepts give evidence for a shared epistemological basis between the major strands in linguistic humor research and CL.

Second, CL unites a number of approaches that treat language as an essential part of cognition, with a strong experiential basis and driven by general principles of conceptual organization, categorization and processing. With its focus on the conceptual and dynamic aspects of language, $\mathrm{CL}$ reacts against the formalist tradition in linguistics (and most notably generative linguistics), which treated language as an autonomous system of structures. For that reason, $\mathrm{CL}$ has from its very onset had a keen interest in phenomena that challenge a formalist and modular view on language structure. Among the complex phenomena that hinge on the interplay of linguistic, cognitive, social, cultural and emotional features, are conceptual metaphor and metonymy, but also humor, irony and sarcasm. Not surprisingly, then, cognitive linguists have repeatedly drawn on verbal and other humor as illustrations of the 'fluid' conceptual system. Importantly, in most of these cases, these analyses serve as a test bed for key concepts in $\mathrm{CL}$ rather than as considerations on the cognitive foundations of humor. In other words, the study of humor and other 'exotic' or 'atypical' phenomena is believed to generate new insights into the dynamics of cognitive processing in general, as Fauconnier (1997: 125) put it:

Errors, jokes, literary effects, and atypical expressions use the same cognitive operations as everyday language, but in ways that actually highlight them and can make them more salient. As data, they have a status comparable to laboratory experiments in physics: things that may not be readily observable in ordinary circumstances, which for that reason shed light on ordinary principles.

As a consequence, there is often no explicit reference to work in humor research or reflection on how these concepts relate to cognitive humor theories. What predominates, is the status of humor as a test case for the soundness of cognitive linguistic concepts, and thus studies in this line only need to account for their relevance within the research paradigm of CL. Next to this line of research, however, there are also a range of publications that critically assess existing humor research from a cognitive linguistic point of view (e.g. Veale 2004, 2012; Brône and Feyaerts 2004; Brône, Feyaerts and Veale 2006; Ritchie 2006; Hamrick 2007; Antonopoulou and 
Nikiforidou 2009; Mayerhofer 2013; Brône, Feyaerts and Veale 2015). These studies essentially focus on the question to what extent constructs from $\mathrm{CL}$ may contribute to linguistic theorizing on humor. This can pertain either to the larger framework of analysis or to specific concepts that may or may not be integrated into existing models.

In this chapter, we will focus primarily on cognitive linguistic treatments of humorous phenomena, irrespective of their specific purpose (as contributions to linguistic humor theory or as illustrations of general conceptual mechanisms). In doing so, we take a somewhat restricted focus in that we present an overview of studies that have a more or less explicit cognitive linguistic seal (see Brône 2012 for a broader overview). The chapter is structured as follows. In a first part, we zoom in on two systematic research programs in Cognitive Linguistics that have dealt with humorous phenomena more extensively, viz. the space structuring model developed by Seana Coulson (2.1.) and the work on information structure and salience by Rachel Giora and colleagues (2.2.). In a second part, we present an overview of studies on specific key phenomena that figure prominently in $\mathrm{CL}$, such as metaphor, metonymy, mental spaces, conceptual blending and grammatical constructions (section 3). The chapter closes off with some further considerations on the potentially fruitful interaction between humor research and Cognitive Linguistics (section 4).

\section{Historical Perspective: Cognitive models of creative meaning construction}

Both Coulson and Giora have a strong profile in experimental cognitive science, but Coulson's work is situated more explicitly in the framework of $\mathrm{CL}$, whereas Giora's work offers a unique and unified model of information structure and access in discourse (revolving around the notion of salience). In what follows, we review some of their seminal work that spans a period of more than two decades.

2.1. Humor and the space structuring model 
Within the larger framework of Cognitive Linguistics, the descriptive model most strongly associated with the study of humor undoubtedly is mental spaces theory and conceptual blending theory (Fauconnier 1994, 1997; Fauconnier and Turner 1998, 2002, cf. 3.2). The most important exponent of this strand of research is Seana Coulson, who developed a model of meaning construction in discourse, based in part on mental spaces and blending theory, and who has presented substantial empirical evidence for the cognitive plausibility of this model. Among the humor types she analyzed as an illustration of the explanatory power of the space structuring model, are one-line jokes, cartoons, wordplay and irony/sarcasm (see Coulson 2015 for an overview). The main strength of this strand of research, rather than presenting truly novel insights into the cognitive mechanisms of humor, resides in the combination of experimental techniques that are used to gain access to the cognitive processing of verbal and visual stimuli (including neurophysiological data, reading times and eye-tracking). The body of empirical evidence supporting the hypotheses generated by the space structuring model does, however, also directly relate to some of the key issues in (linguistic) humor research. This is most notably the case for the phenomenon of frame-shifting, which is largely identical to the central notion of script-switching in the SSTH/GTVH.

The space structuring model is strongly rooted in frame semantics and mental spaces theory, and argues that meaning construction is a process of actively evoking background knowledge (frames) and distributing that knowledge over different mental spaces. These epistemological roots of the model are combined into a coherent model of meaning construction in context. More specifically, the model accounts for the tension between lexical semantics and discourse constraints in the construction of meaning: it describes how, on the one hand, lexical items actively contribute to the construction of the discourse representation, through the activation of frames in long-term memory, and on the other hand, the discourse representation guides as well as facilitates access to the semantics of lexical items that are compatible with that representation. Coulson argues that this tension can be described in terms of the (re)construction of, as well as navigation through, a complex network of mental spaces. 
Coulson draws on different types of creative language use as prime examples of 'online' meaning construction for which the space structuring model provides a descriptive framework. These 'exotic' phenomena thus serve as an illustration of the complex interaction between language and context in meaning construction, and at the same time as a reaction against the longstanding tradition in cognitive science (including cognitive linguistics) to build theories on highly artificial examples stripped of a realistic context of use (Coulson 2000: 278). As an example of the type of phenomena under scrutiny, take the punchline joke in (1). While reading or hearing the first words of the joke, the reader/hearer gradually builds up a cognitive representation of the described situation, and thus builds up discourse expectations in a specific direction. This expectation becomes apparent at the punch line, where the final nominal phrase (his wife) forces the reader/hearer to re-construe the cognitive model in a way that is radically different from the initial construal. This process is described by Coulson as frame-shifting.

(1) When I asked the bartender for something cold and full of rum, he recommended his wife. The concept of frame-shifting is largely identical to Raskin's script-switching (Raskin 1985), which has figured prominently in (linguistic) humor research. Coulson does, however, stress more strongly the conceptual flexibility that is crucial to the frame-shifting process. In other words, semantic (re)construction is not merely a matter of activating semantic frames or slot-filler structures from long-term memory, but rather revolves around the careful integration of cognitive models, based on conceptual mappings between and in mental spaces (Coulson, Urbach and Kutas 2006: 232). In other words, cognitive discourse models are actively and dynamically construed rather than largely accessed from knowledge structures in memory (and idea that is also stressed in Attardo 2001: 6-7). In the case of (1), for instance, there is an apparent opposition between the frames of RECOMMENDING FOOD/DRINK and that of INSULT. More important, however, from the perspective of the space structuring model, is the observation that elements may acquire a local meaning that only functions as part of the (re)construed cognitive discourse model. In this specific example, by linking the phrases full of rum and his wife the former acquires the locally relevant meaning "alcoholic", triggering the insult reading of the joke. 
Next to the theoretical relevance of the space structuring model as framework strongly rooted in $\mathrm{CL}$, Coulson's work stands out because of its empirical rigor. Coulson and colleagues have investigated the psychological reality of frame-shifting and other relevant phenomena. It is hypothesized that frame-shifting will have an impact on cognitive processing load and this hypothesis was tested by comparing test subjects' response to punch line jokes versus texts that do not require a process of frame-shifting (as e.g. in a variation on (1): When I asked the bartender for something cold and full or rum, he recommended his daiquiri). This response was measured using different experimental paradigms, including reading-time data (with subjects taking longer to read punch line jokes in comparison to non-joke endings, Coulson and Kutas 1998), eyetracking data (more regressive eye movements upon reading the punch line, Coulson et al. 2006) and event-related brain potentials (ERP, neural indices of semantic reintegration after processing the final word of the joke, Coulson and Kutas 2001).

All in all, the studies by Coulson and colleagues present strong empirical evidence for the psychological reality of frame-shifting, and thus not only support the main claims proposed in the space-structuring model, but also empirically validate some of the key assumptions made in (cognitive) humor research. Most importantly, however, this line of work serves as a strong argument in favor of a usage-based cognitive science, taking the conceptual fluidity of language users as a rule rather than as an exception.

\subsection{Humor and the salience principle}

A second major line of research on humor and creative language in $C L$ has been established by Rachel Giora and her colleagues, and was inspired by lexical semantics and psycholinguistics (Giora 1997, 2003). Giora's starting point is a general principle of semantic organization (in this case an information structure and salience principle) which manifests itself particularly clearly in humor and irony. In what follows, we briefly discuss two related hypotheses that emanated from this research program, viz. the Marked Informativeness Hypothesis and the Optimal Innovation Hypothesis. 
In an early publication, Giora (1991) analyzes the effect of surprise in punch line jokes in terms of the typical information structure of texts. According to the principle of graded informativeness, normal texts are typically built up in such a way that gradually more informative elements are added to the text. In terms of prototype theory elements with a high information value exhibit properties that differ from the prototype of the category. As an effect, they are considered least likely to occur and would generate an effect of surprise when encountered. The major difference between 'normal' texts and joke texts, according to Giora, resides in this degree of informativeness. Whereas the former exhibit a gradual build-up in the information value of the textual elements that are presented, the latter display a more marked semantic structure. This observation led to the formulation of the Marked Informativeness Requirement for narrative jokes, which states that a well-formed joke

obeys the Relevance Requirement and violates the Graded Informativeness Requirement [...] in that it ends in a markedly informative message and causes the reader to perform a linear shift: the reader is made to cancel the first unmarked interpretation upon processing the second marked interpretation.

(Giora 1991: 470)

The Relevance Requirement stipulates that the punch line is in fact compatible with the rest of the text, although it is marked in the sense that it differs significantly from the information that is present in the established discourse representation (thus violating the Graded Informativeness Requirement). The effect of this markedness of the final element in comparison to the prototypical text category is stipulated in the second part of the Marked Informativeness Requirement: it forces a linear shift or abrupt transition from the initial discourse representation to a forced new one (with a large cognitive distance between the two, Giora 1991: 471). In example (1) above, the initial interpretation of the phrase cold and full of rum relates to the typical context of a bar. Elements such as bartender and recommend are prototypical, and thus unmarked and low in terms of information value, within the setting of ordering a drink at a bar, 
whereas the joke interpretation, which only becomes foregrounded at the punch line of the joke, is marked in terms of information value.

The Marked Informativeness Requirement relates to some of the above-mentioned work by Coulson on the space structuring model through its cognitive assumptions. According to the hypothesis, jokes differ from other traditional tropes such as metaphor and wordplay in the degree of cognitive activation of different interpretations. Whereas in metaphor and wordplay, there is simultaneous activation of multiple meanings, jokes hinge on the suppression of the unmarked (or salient) interpretation in favour of the marked one that is activated through the punch line. Giora (2003: 170-175) presents empirical evidence for the suppression hypothesis, and this is supported by other studies as well, including Coulson and Kutas $(1998,2001)$ and Vaid et al. (2003).

The ideas developed in the Marked Informativeness Requirement formed the basis for a research agenda on information processing in/and creativity, which is formulated most strongly in the Optimal Innovation Hypothesis (Giora 2003; Giora et al. 2004, 2015). This hypothesis states that the subjective effect of pleasure generated by creative stimuli can be explained by a delicate balance (or tension) between innovation on the one hand and salience (defined as a form of cognitive entrenchment) on the other. The central concept of salience, developed into a fullfledged research program (Giora 1997, 2003), is proposed as a principle of semantic organization in the mental lexicon. Some meanings are argued to be more salient than others, which can be explained by a number of parameters, including frequency, prototypicality, conventionality or familiarity (Giora 2003: 15-22). Importantly, in terms of lexical access, salient meanings are shown to be more easily accessible than less salient ones. Giora and her colleagues have provided evidence for the role of salience in the semantic processing of a range of figurative language phenomena, including metaphor, irony, sarcasm, jokes and wordplay. The Optimal Innovation Hypothesis integrates the salience hypothesis into a model of creativity and stipulates that aesthetic innovation hinges on salience for its effect of pleasure.

The major difference between the Optimal Innovation Hypothesis and existing models on expressivity and innovation (discussed in detail in Giora 2003: 176-183) is situated exactly in its 
focus on the balance between the familiar and the expressive. In other words, aesthetic effects are not primarily a function of innovation in itself, but rather emerge from innovation that is firmly rooted in entrenched knowledge (i.e. the salient):

(1) The Optimal Innovation Hypothesis - Pleasurability is sensitive to optimal innovation.

(2) Optimal innovation -A stimulus would be optimally innovative if it involves

(a) a novel - less or nonsalient - response to a given stimulus, which differs not only quantitatively but primarily qualitatively from the salient response(s) associated with this stimulus and

(b) at the same time, allows for the automatic recoverability of a salient response related to that stimulus so that both responses make sense

(Giora et al. 2004: 116)

The examples in (2) illustrate the tension between familiarity and creativity that constitutes the essence of optimal innovation.

(2) a. Weapons of mass destruction (salient, familiar expression)

b. A Weapon of mass destruction (morphological variant of the salient expression)

c. Weapons of mass distraction (optimal innovation)

d. Absorption of mass produced wine (pure innovation)

The phrase in (2a) is familiar to most English speakers and its conventional meaning is most likely stored in speakers' mental lexicon. According to the Optimal Innovation Hypothesis, the experience of aesthetic creativity can be explained as an effect of variation or deautomatization of a salient stimulus. This variation is principled, however. On the one hand, a novel element should differ from the salient meaning associated with the familiar element/word/phrase. In the case of $(2 b)$, for instance, the morphological variation by using a singular form instead of the more commonly used plural does not yield a conceptually different meaning, and is thus not 
generally considered to be creative. In (2c), however, the novel form does differ both quantitatively and qualitatively from the conventional, salient phrase (e.g. as an ironic comment on mainstream propaganda in popular media). Crucially, the new form at the same time evokes a novel meaning and allows for the recoverability of the salient phrase on which it builds (readers or hearers automatically activate the familiar phrase "weapons of mass destruction" upon reading or hearing "weapons of mass distraction"). The relevance of recoverability, or the relative degree of innovation, is made clear in examples such as (2d). Here, the phrase exhibits some similarity to the familiar phrase, both in sound, rhythmic and constituent structure, but the new phrase does not (clearly) allow for the recoverability of the salient (requirement $2 \mathrm{~b}$ of the hypothesis).

Giora and her collaborators designed a series of experiments to test the cognitive reality of optimal innovation (an overview of which can be found in Giora et al. 2004, 2015). First, test subjects typically rate optimally innovative stimuli like (2c) as more pleasurable in comparison to the other variants $(2 a, 2 b, 2 c)$. Importantly also, given the focus on graded innovativeness in Giora's hypothesis, salient stimuli (like 2a) should elicit a higher degree of aesthetic pleasure than pure innovations (as 2d). This again is confirmed in a rating task reported in Giora et al. (2004). Second, the results from experiments measuring cognitive processing cost (including self-paced reading) suggest that optimal innovation comes with a cognitive cost: optimally innovative stimuli require the activation of both the familiar (salient) and the novel response. This simultaneous processing is reflected in the average length of reading times of optimally innovative stimuli in comparison to unambiguously salient ones (cf. also Brône and Coulson 2010).

The Optimal Innovation Hypothesis does not only allow for a strictly cognitive reading, though. The above-mentioned tension between the familiar and the novel, the deautomatization of salient responses, provides creativity with the power of subversiveness (Giora 2003: 182-183). This deviation of routine thinking as a source of creativity, humor and aesthetics is of central interest to both pragmatics and $\mathrm{CL}$. In pragmatics, it is known as norm violation; in Cognitive Linguistics as the tension between conventionality and innovation (see Brône 2012, Veale, Brône 
and Feyaerts 2015 and Veale 2012 for an overview). As mentioned in section 1 above, cognitive linguists resort to cases of humor and creativity as test cases or show cases for

(i) the conceptual flexibility or mental agility that is central to constructivist approach to semantics advocated in CL (Veale, Brône and Feyaerts 2015). Despite subverting linguistic norms and habitual patterns of thinking and speech, humor is still produced and processed on the fly and without apparent effort. Phenomena that at first glance appear to parasitize on the linguistic system, may in fact provide a unique perspective on it.

(ii) the flexibility of the theoretical constructs developed in the paradigm of CL. Showing that these constructs (like mental spaces, conceptual blending, conceptual metaphor, grammatical constructions, etc.) can be applied to creative and unconventional instances of language use, is indicative of their descriptive power. In other words, looking at phenomena that at first glance seem to undermine the linguistic system, may in fact provide evidence for the same systematics.

These two motivations for studying humorous phenomena in language figure prominently in other studies in the broad field of Cognitive Linguistics. In what follows, we provide an overview of phenomena that have played and continue to play a central role in $\mathrm{CL}$ in general, and which have been shown to be instructive for the analysis of (at least some types of) humor as well.

\section{Core Issues and Topics: Applying concepts from Cognitive Linguistics to humor research}

Recent years have witnessed an increase in studies approaching humor from a cognitive linguistic perspective (cf. Brône et al. 2006, 2015; Veale 2012; Brône 2012). The following overview focuses on three of the research programs in Cognitive Linguistics, applied to the study of humor, viz. (i) metaphorical and metonymic mappings, (ii) mental spaces, and (iii) grammatical constructions.

3.1. Conceptual mappings in humor: the case of metaphor and metonymy 
One of the landmarks of Cognitive Linguistics is Lakoff and Johnson's seminal Metaphors We Live By (1980), which set the agenda for the study of metaphor as a conceptual mechanism central to thought and language. Cognitive linguists have dealt with the conceptual status, discursive function, neurological and psychological reality, as well as the practical application of metaphor (and to a lesser extent metonymy). In its most basic definition, conceptual metaphor is seen as a systematic and asymmetric mapping between two conceptual domains, one of which serves as a source that provides the necessary structure for the target domain. A classical example of such a mapping is LOVE AS A JOURNEY, described in Lakoff and Johnson (1980), which underlies expressions such as this is how far we have come, our marriage is on the rocks, we're at the crossroads, etc. In each of these phrases, some of which are conventionalized, while others are not, the abstract domain of LOVE is conceptualized by resorting to concepts from the more concrete experiential domain of TRAVELING.

The central principle of double domain activation in metaphor is reminiscent of cognitive, scriptbased humor theories, which also focus on the activation of two (typically opposed) scripts that are connected in the process of incongruity resolution (Attardo et al. 2002). Although this theoretically interesting conceptual relationship between humor and metaphor has been addressed by several scholars, and from different perspectives for some time (Koestler 1964; Hofstadter and Gabora 1989; Giora 1991, 2003; Attardo 2015; Müller 2015), the key question on the boundaries between the phenomena has not received systematic attention. A notable exception is Pollio (1996), who uses insights from conceptual metaphor theory to argue that the main difference between metaphor and humor is situated in the profiling of domain boundaries. Metaphors, it is claimed, integrate information from the source and target domain to form a unified conceptual entity, suppressing the apparent domain boundaries, whereas humor in fact emphasizes the domain discrepancies or oppositions.

Attardo (2015) takes a somewhat different approach by addressing the question what makes some metaphors humorous while others are not. Humorous metaphors, it is argued, can be used as an umbrella term for different phenomena: metaphors that are funny in and of themselves, metaphors that describe a referent that is inherently funny, and failed metaphors. Attardo problematizes the conceptual boundaries of the category of humorous metaphors, and argues 
that the criterion of 'semantic distance' (which is also present in Pollio's account) is difficult to operationalize. As an alternative, Attardo proposes to treat humorous metaphors as prototypical category, sharing family resemblances rather than strict definitional features and sharp boundaries. With this approach, Attardo relates his account to one of the foundational principles of $\mathrm{CL}$, viz. linguistic categorization inspired by prototype theory.

Veale et al. (2006) take the conceptual substrate of metaphor as a basis for studying the subversive potential of humor as described by Giora above. More specifically, they argue that in interactional humor, deep-rooted metaphorical structures can be used as a cue for trumping an adversary or partner. In sequence (3), speaker B distorts the conceptual mapping between source and target in the conventional metaphorical expression a blessing in disguise used by speaker $\mathrm{A}$ (target: SOMETHING NOT IMMEDIATELY APPARENT, source: CONCEALMENT). By simply adding the modifying adjectival phrase bloody good, the semantics of the idiomatic expression changes radically, because the addition foregrounds the literal meaning components of the idiom, which are not typically profiled in conventional usage. Such figure/ground reversals between literal and metaphorical readings, or between an idiomatic and componential analysis, in fact play a prominent role in a whole range of humorous phenomena, even when no figurative component is involved, as in (4) (Veale et al. 2006; Veale 2012; Brône 2008). In (4), the one-line joke subverts the classical interpretation of waterpolo as a subdiscipline of aquatic sports, in favor of an ad hoc reading that foregrounds the two components of the compound waterpolo, and used the conventional non-compound reading of polo as an equestrian ball game.

(3) A: (consoling tone) Perhaps it is a blessing in disguise, dear.

B: (angry tone) Well, it must be a bloody good disguise then.

(4) Tim hasn't played waterpolo since that tragic day when his horse drowned.

In comparison to the massive amount of publications dealing with metaphor in $\mathrm{CL}$, its conceptual counterpart metonymy received substantially less attention in the literature. For the analysis of 
humor, however, the definition of metonymy as a cognitive construal mechanism involving the selection of a salient reference point to refer to a different concept in the same frame (or the frame as a whole, Langacker 1993), does provide interesting analytical potential. More specifically, proposing a conceptual approach to metonymy as a process of "mentally accessing one conceptual entity via another entity" (Langacker 1993: 30), also covers pragmatic phenomena such as inferences and conversational implicatures (Gibbs 1999, Panther and Thornburg 2003). Since humor interpretation involves complex inferential activity, it may be useful to inquire into the metonymic basis of pragmatic processes.

Barcelona (2003) presents a theoretical argument for the metonymic basis of pragmatic inferences, and uses joke interpretation as a prime illustration. He argues that joke interpretation is facilitated by established metonymic connections within specific experiential domains, and that these connections play a constitutive role in the process of frame shifting or script switching. Example (5), taken from Barcelona (2003: 93-97) illustrates the inference guiding role of metonymy.

(5) Opposition MP (referring to the Prime Minister): "But what can we expect, after all, of a man who wears silk underpants"

The Prime Minister (rising calmly): "Oh, I would never have thought the Right Honorable's wife could be so indiscreet!"

The humorous provocation by the MP, which opens the sequence in (5), builds on the stereotypical cultural model of masculinity, which prescribes specific rules of conduct, appearance and clothing. According to that stereotype, real men do not wear silk underwear, which thus implies that according to the MP, the Prime Minister is not a real man. In his response, the prime minister opportunistically exploits this metonymic reference point (WEARING SILK UNDERPANTS stands for PERSONALITY TRAIT by linking the MP's supposed knowledge to the indiscretion of the latter's wife ('you know that I wear silk underwear because your wife, with 
whom I have a sexual relationship, has confessed this to you'). In this and other cases, metonymic patterns guide the reorientation process that is central to the humorous effect.

The concept of metonymic inferencing as reference-point structure is explored in Brône and Feyaerts (2004) and Feyaerts and Brône (2005) as well. Based on an analysis of one-line jokes and cartoons, they argue that humorous effects may be attributed to marked referencepoint structures, which complicate the interpretation process. The examples in (6) are humorous insults referring to the ugliness (6a) and stupidity (6b) of the butt of the joke. Interestingly, in both cases the target concept is activated by means of an unconventional metonymic reference-point in a causal chain of events, being either the effect (6a: effect of seeing an ugly baby) or the cause (6b: bumped his head, so causing brain damage). The result of these unconventional or marked, but nevertheless retraceable metonymic reference point structures, is a balanced processing difficulty, which again is reminiscent of Giora's Optimal Innovation Hypothesis (supra 2.2.).

(6) a. Surely your father shot the stork after seeing you.

b. Looks like you weren't strapped in during launch.

\subsection{Mental spaces and conceptual blending in humor}

Fauconnier proposed a model for the analysis of conceptual structuring in thought and language $(1994,1997)$. He introduced the concept of mental spaces to account for the way in which we structure and partition information in smaller, manageable packages. These structures are argued to "proliferate when we think and talk, allowing a fine-grained partitioning of our discourse and knowledge structures" (Fauconnier 1997: 11). It is argued that partitioning discourse in separate but connected mental spaces is essential to a whole range of phenomena, including analogy, conditional and counterfactual reasoning, modality, indirect speech and thought, and the differentiation of different viewpoints (e.g. attributing different viewpoints to characters in a narrative). 
The above-mentioned space structuring model developed by Seana Coulson (2.1.) is strongly rooted in mental spaces theory, and provides a framework for the analysis of jokes as well as irony (Coulson 2005). Next to this research program, only few studies have looked into the relevance of mental spaces. Ritchie (2006) is a notable exception, in that he takes the abovementioned mental space approach to narrative viewpoints to account for jokes that revolve around character misinterpretation within the joke story world, and proposes an account of viewpoint shifts/reinterpretations. The relevance of a mental spaces approach, according to Ritchie, resides in the explicitation of the level(s) at which the typical reinterpretation process in jokes takes place. That is to say, whereas traditional humor theories mainly focus on the reader's perspective, who has to perform a script switching or frame shifting operation after encountering the punchline (i.e. a forced reinterpretation), Ritchie shows that the initial misinterpretation can also be attributed to a story character in the joke (with the reader or hearer consciously observing that misunderstanding). Using mental spaces as an analytical tool for partitioning the discourse may help to capture this stratification into different viewpoints and belief sets, as the reinterpretation process does not necessarily have to be directly in the mental space of the audience, but rather, it suffices that it happens in a viewpoint that is accessible to that audience.

Following up on Ritchie's account, Brône (2008) outlines a descriptive model for the analysis of interactional humor, based in part on mental spaces theory and in part on Herbert Clark's Joint Action Hypothesis (Clark 1996). Among the phenomena that are analysed in terms of complex constellations of viewpoint mental spaces, is a form of teasing referred to as hyperunderstanding:

(7) Ken: and I'm cheap, - - -

Margaret: I've always felt that about you,

Ken: oh shut up,

(- - laughs) fifteen bob a lesson at home, -

(Clark 1996: 353) 
The category of hyper-understanding was introduced to cover instances of interactional humor that revolve around one speaker taking advantage of potential ambiguities or other conceptual weak spots in a previous speaker's utterance. In the case of the example in (7) shows, the second speaker (Margaret) playfully echoes the utterance of the first speaker (Ken) through the use of the anaphoric element that, while at the same time subverting the initially construed interpretation of that element, highlighting the metaphorical rather than the literal reading of cheap. In terms of its mental space configuration, the phenomenon of hyper-understanding centrally involves the differentiation of viewpoints, and the construal of a pretend space in which the teaser playfully assumes that the initial speaker in fact intended that secondary reading. Examples such as these show the potential of mental spaces theory as an analytical tool to account for the complex interplay of different communicative layers of action that is typical of interactional humour. This playful layering at times is marked through the use of nonverbal signals, such as raised eyebrows (Tabacaru and Lemmens 2014).

As an offshoot of mental spaces theory, Fauconnier and Turner proposed the so-called conceptual blending or conceptual integration theory (Fauconnier and Turner 1998, 2002; Turner 2015), which focuses on the way in which information from different mental spaces may be integrated into hybrid cognitive models. This model postulates that in natural forms of cognition and language use, conceptual content from different resources is integrated via a set of partially compositional processes. Among the cognitive phenomena that are argued to involve conceptual integration processes are the classical construal phenomena described in CL (metaphor, metonymy, conditional reasoning, etc.). Conceptual blending theory aims to uncover an underlying mental operation in various manifestations of creative or imaginative cognition. Different 'acts of creation', from wit and humor to the scientific and artistic genius, involve the integration of input from different sources to yield novel conceptualizations.

Conceptual blending theory attracted the attention of humor scholars, in part because of its flexibility and broad analytical range, in part because of its appealing visual representations (with 
mental spaces represented as circles that are connected in multiple ways). The framework has been used to account for the phenomenon of frame-shifting (cf. 2.1), irony and sarcasm, wordplay of the type addressed in the Optimal Innovation Hypotheses (cf. 2.2) and a range of other phenomena in which the local integration of conceptual structure yields a witty, expressive or humorous effect. Fauconnier and Turner (2002), Coulson and Oakley (2003), Feyaerts and Brône (2005), Brône and Feyaerts (2005), and Brône and Coulson (2010), provide blending analyses of local ambiguities that revolve around the source-target resonance in metaphorical construal. To take the example of metaphorical wordplay, a headline as in (8) crucially relies on the reactivation of the literal basis of what is essentially a metaphorical expression. In the context of economic news reports, the verb to puncture has a contextually salient metaphorical meaning ('cause to diminish'). However, the metonymically motivated link between the producer Michelin and its primary product (tires) re-profiles the literal reading of puncture.

(8) US slowdown punctures Bridgestone's profits

This strategy of relating encyclopaedic knowledge to the literal meaning components of a metaphorical expression was labelled double grounding (Feyaerts and Brône 2005), referring to the double projection of one key element (puncture in (8)) onto two input spaces of a complex integration network. Brône and Coulson (2010) tested the psychological reality of double grounding, using a reading-time experiment and rating task. It was hypothesized that double grounded metaphors (such as (8)) would require a higher processing cost and produce higher wittiness ratings in comparison to single grounded metaphors (like e.g. US slowdown punctures Cold Stone's profits). The results of this experiment indeed yielded longer average reading times and higher wittiness ratings for double grounded metaphors, thus providing evidence for a conceptual integration process. 
Apart from a range of verbal phenomena, conceptual blending theory has been applied to multimodal phenomena as well, including cartoons (Hofstadter and Gabora 1989; Hünig 2002; Bergen 2004; Marín-Arrese 2003, 2006; Brône and Feyaerts 2005; Coulson \& Oakley 2003), comics (Veale et al. 2013), and multimodal advertisements (Fauconnier and Turner 2002, Lundmark 2005). Multimodal representations are often highly compressed cues that need to be unpacked in multiple knowledge structures in order to be understood.

\subsection{Grammatical constructions in humor}

When looking at the body of literature on the linguistic aspects of verbal humor, it is apparent that the grammatical particularities of humor have only received little attention in comparison to the phonetic, lexical, semantic and pragmatic dimensions. Nevertheless, grammatical patterns may be of importance in generating humorous effects, either in deviations from conventional patterns of usage, or as productive formulaic patterns for specific joke types. Both of these dimensions were recently addressed in a number of studies that take insights from construction grammar and Cognitive Grammar and apply them to particular aspects of the grammar of humor.

One of the key assumptions of both Construction Grammar (Goldberg 1995) and Cognitive Grammar (Langacker 1987, 2008) is that the basic units of language are symbolic pairings of form and meaning, rather than atomic syntactic structures and combinatory rules. These symbolic pairings, referred to as grammatical constructions, constitute the primary repository of linguistic knowledge on different levels of linguistic organization, from the lexicon (words as conventionalized form-meaning couplings) to larger constructional patterns (referred to as the constructicon of the language), and even recurrent discourse patterns (or discourse constructions, Östman 2005). As a consequence, construction grammar does not adhere to the classical modular view which draws relatively strict boundaries between lexicon and syntax.

Antonopoulou (2002), Antonopoulou and Nikiforidou (2009) and Antonopoulou, Nikiforidou and Tsakona (2015) present a construction grammar view on the first dimension sketched above: verbal humor may draw on specific discrepancies between the semantics of an abstract grammatical construction and the semantics of lexical items that are used in instantiating that 
construction. In one of the examples under scrutiny (9), taken from a narrative by Raymond Chandler, the grammatical construction that is conventionally used for expressing caused motion (Goldberg 1995), is exploited for humorous purposes.

(9) Keith squats forward and fights his mother's thigh up into the car, while Frank leans forward...

(Antonopoulou and Nikiforidou 2009: 298)

The constructional pattern in (13), consisting of a verb with a double object ([SUBJ [V OBJ OBL]]), is in its unmarked usage typically instantiated by verbs that have the causing of motion as part of their semantics, like e.g. to throw (Jack threw the napkin off the table), which licenses two thematic roles (agent, patient), corresponding to the subject and object position of the construction. However, the construction can also be instantiated with other verb types, like they laughed the poor guy out of the room, where the valence of the intransitive verb laugh is 'augmented up' to that of a transitive verb because the construction in which it is embedded requires a transitive relationship. This phenomenon is referred to as coercion or type-shifting (Michaelis 2005). In (13) the integration of fight, which does not conventionally have a directional complement, into the caused motion construction triggers a humour-relevant incongruity: the construction profiles an external causal force for an action (lifting a thigh) that under normal circumstances does not require such an external force. As a consequence, the constructional semantics triggers the construal of the object of movement (mother) as an indiscrete mass.

The example in (9) revolved around the discrepancy between a schematic constructional pattern and its instantiation with specific lexical elements. Construction grammar posits a continuum between schematic and fixed constructions, with idiomatic expressions obviously having a more fixed form and conventionalized idiomatic reading (also referred to as (semi-)substantive constructions). Humor frequently draws on these conventionalized patterns and couplings, as was already discussed in the sections on Giora's Optimal Innovation Hypothesis (2.2) and 
metaphor (3.1.). Antonopoulou and Nikiforidou (2009) argue that construction grammar provides an adequate model for a uniform analysis of these different manifestations, with the additional advantage that construction grammar can naturally integrate insights from frame semantics (on which it builds): “A significant contribution of CxG [Construction Grammar, GB] to humour is that it fills in a noticeable gap in the GTVH and in any theory which focuses on content rather than form, thereby underrating the role of language" (Antonopoulou and Nikiforidou 2009: 310). Antonopoulou, Nikiforidou and Tsakona (2015) apply the same rationale to larger discourse units and argue that conventional discourse patterns from a specific genre may be exploited in different genres, so as to achieve a humorous effect.

A second potentially interesting perspective on grammar and humor involves the productive use of specific grammatical constructions for specific joke formats. Bergen and Binsted $(2004,2015)$ focus on the phenomenon of scalar humor, which is based on the use of a construction that expresses a position on a scale (the $X Y Z$-construction: ' $X$ is so $Y$ that $Z$ '). This conventional construction, used in non-humorous language as in (10a), profiles a scalar inference between the first and second phrase of the construction: $\mathrm{Z}$ illustrates that $\mathrm{X}$ has a high degree of $\mathrm{Y}$. This conventionalized pragmatic relation evoked by the XYZ-construction is used to create hyperbolic cause-effect relations as in (10b-e).

(10) a. We danced so long, my feet got sore

b. Yo' mama's so old, she knew Burger King when he was still a prince

c. Yo' mama's so old, she has a picture of Moses in her yearbook

c. Yo mama's so fat, a picture of her fell off the wall

(Bergen and Binsted 2004)

In the examples in (14b-c) the Z-component of the construction (she knew Burger King when he was still a prince, she has a picture of Moses in her yearbook) presents scenes that do not fit the 
normal scope of $Y$ (in this case the mean length of a human lifetime). (14d) shows that such a hyperbole can be based on a false presupposition (viz. that representations have a weight that is proportional to the object represented). Studies such as those by Bergen and Binsted can serve as illustrations of the flexibility and creativity of conceptual construal, overriding conventionalized semantic-pragmatic features within the boundaries of a grammatical construction.

\section{The future of cognitive linguistic humor research}

Although Cognitive Linguistics has maintained a relatively steady interest in creative phenomena such as humor and irony over the last two decades, the studies presented thus far have been largely programmatic, in the sense that they aim to show the potential of a cognitive linguistic approach. There is thus a substantial need for further empirical validation and theoretical integration. Looking at the current research agenda of $\mathrm{CL}$ in general, we see at least three priorities for future research.

First, from the very onset, $\mathrm{CL}$ presents itself as a strongly usage-based framework (Langacker 1987). At a theoretical level, this means that all linguistic knowledge emerges from actual usage, in a process of schematization and abstraction from fully instantiated usage events. From an analytical perspective, the usage-based postulate has led to an increase in large-scale empirical work, focusing on language use in context, language variation and change, using a variety of methods such as corpus studies, psycho- and neurolinguistics experimentation, and simulation models (see Tummers et al. 2005 for a technical state-of-the-art). Many of the topics discussed in this chapter are still in need of further empirical support, both in terms of their empirical scope in different usage settings, and their cognitive plausibility. The two more systematic research programs developed by Coulson and Giora, in which theoretical concepts and specific cognitive hypotheses are tested using a variety of empirical methods, set an example for researchers interested in pursuing this direction.

Second, the empirical turn in CL towards the analysis of more and truly usage-based data has paved the way for the study of spoken language. Whereas CL has long suffered from the written- 
language bias that has been typical for much work in linguistics, the relatively recent availability of large corpora of spoken language has led to an increased interest in the dynamics of spoken language as the primary form of language use. Large-scale corpus studies focusing on the interactional grounding of humorous phenomena in spontaneous face-to-face interaction, are still scarce (Attardo 2008, Brône and Oben 2013, Feyaerts and Oben 2014). Linked to this increasing interest in spoken language is a turn towards multimodality interaction, studied from a cognitive linguistic perspective (see Feyaerts, Brône and Oben, in press for an overview). Only very few studies have looked into the interaction between verbal and nonverbal markers (such as hand gestures, head movements, facial expressions and eye gaze) in the realization of humorous or ironic utterances (Attardo et al. 2011, Tabacaru and Lemmens 2014). This opens up a large and new area of research that is relevant to both cognitive linguists and humor researchers.

A third and final point pertains to the interdisciplinary collaboration in the broad field of CL. Cognitive linguists increasingly cooperate with researchers from neighboring fields to address specific aspects of the cognitive, social and interactional dimensions of language, based on the foundational principle of $C L$ that "language is an integral facet of cognition which reflects the interaction of social, cultural, psychological, communicative and functional considerations" (source: motto of the Cognitive Linguistics Series, Mouton de Gruyter). For the analysis of humor, such a broad multi-angle approach is indispensable, as it has often been argued that humor requires a holistic, integrated approach (Brône, Feyaerts and Veale 2006). The GTVH may serve as an example, in the sense that is a model grounded in linguistics, but is integrates insights from different variety of fields in the operationalization of the knowledge resources (KRs) it postulates. A challenge for cognitive linguists thus is the integration of insights from case studies (as the ones presented above) into a larger model (being either the GTVH or alternative models), as well as the incorporation of ideas and methods from other fields. Only by doing so, Cognitive Linguistics will be able to claim an original contribution to the field of humor research, and not fall victim to the common problem of duplicating existing insights, to which humor research has susceptible in the past. 


\section{References}

Antonopoulou, Eleni and Kiki Nikiforidou 2009 Deconstructing verbal humour with contruction grammar. In: Geert Brône and Jeroen Vandaele (eds.), Cognitive Poetics. Goals, Gains and Gaps, 289-314. (Applications of Cognitive Linguistics 10). Berlin/New York: Mouton de Gruyter.

Antonopoulou, Eleni, Kiki Nikiforidou and Villy Tsakona 2015 Construction grammar and discoursal incongruity. In: Geert Brône, Kurt Feyaerts and Tony Veale (eds.) ,Cognitive Linguistics and Humor Research, 13-48. Berlin: Mouton de Gruyter.

Attardo, Salvatore 1994 Linguistic Theories of Humor. (Humor Research 1). Berlin/New York: Mouton de Gruyter.

Attardo, Salvatore 2001 Humorous Texts: A Semantic and Pragmatic Analysis. (Humor Research 6). Berlin/New York: Mouton de Gruyter.

Attardo, Salvatore 2005 Humor. In: Jan-Ola Östman and Jef Verschueren (eds.), Handbook of Pragmatics 2003-2005, 1-25. Amsterdam/Philadelphia: John Benjamins.

Attardo, Salvatore 2008 A primer for the linguistics of humor. In: Victor Raskin (ed.), $A$ Primer for Humor Research, 101-156. Berlin/New York: Mouton de Gruyter.

Attardo, Salvatore 2015 Humorous metaphors. In: Geert Brône, Kurt Feyaerts and Tony Veale (eds.), Humor and Cognitive Linguistics, 91-110. Berlin: Mouton de Gruyter.

Attardo, Salvatore and Victor Raskin 1991 Script theory revis(it)ed: joke similarity and joke representational model. Humor. International Journal of Humor Research 4-3: 293-347.

Attardo, Salvatore, Christian F. Hempelmann and Sara Di Maio 2002 Script oppositions and logical mechanisms: Modeling incongruities and their resolutions. Humor. International Journal of Humor Research 15-1: 3-46.

Attardo, Salvatore, Lucy Pickering and Amanda Baker 2011 Prosodic and multimodal markers of humor in conversation. Pragmatics and Cognition, 19 (2), 224-247.

Barcelona, Antonio 2003 The case for a metonymic basis of pragmatic inferencing: Evidence from jokes and funny anecdotes. In: Klaus-Uwe Panther and Linda Thornburg (eds.), Metonymy and Pragmatic Inferencing, 81-102. Amsterdam/Philadelphia: John Benjamins.

Bergen, Benjamin K. 2004 To awaken a sleeping giant. Cognition and culture in September 11 political cartoons. In: Michel Achard and Susanne Kemmer (eds.), Language, Culture, and Mind, 23-35. Stanford: CSLI Publications.

Bergen, Benjamin K. and Kim Binsted 2004 The cognitive linguistics of scalar humor. In: Michel Achard, and Susanne Kemmer (eds.), 79-92. Language, Culture and Mind. Stanford: CSLI Publications.

Bergen, Benjamin K. and Kim Binsted 2015 Embodied grammar and humor. In: Geert Brône, Kurt Feyaerts and Tony Veale (eds.), Cognitive Linguistics meets Humor Research. Current Trends and New Developments, 49-68. Berlin/New York: Mouton de Gruyter.

Brône, Geert 2008 Hyper- and misunderstanding in interactional humor. Journal of Pragmatics 40-12: 2027-2061.

Brône, Geert 2012 Humour and irony in cognitive pragmatics. In: Hans-Jörg Schmid (ed.), Cognitive Pragmatics, 463-504. Berlin: Mouton de Gruyter. 
Brône, Geert and Seana Coulson 2010 On the cognitive processing of deliberate ambiguity in newspaper headlines: the case of double grounding. Discourse Processes 47: 212-236.

Brône, Geert and Kurt Feyaerts 2003 The cognitive linguistics of incongruity resolution: Marked reference-point structures in humor. University of Leuven, Department of Linguistics Preprint 205. 58 pages.

Brône, Geert and Kurt Feyaerts 2004 Assessing the SSTH and GTVH: A view from cognitive linguistics. Humor. International Journal of Humor Research. 17-4: 361-372.

Brône, Geert and Kurt Feyaerts 2005 Headlines and cartoons in the economic press: Double grounding as a discourse supportive strategy. In: Guido Erreygers and Geert Jacobs (eds.), Language, Communication and the Economy, 73-99. Amsterdam/Philadelphia: John Benjamins.

Brône, Geert, Kurt Feyaerts and Tony Veale 2006 Introduction: Cognitive linguistic approaches to humor. Humor. International Journal of Humor Research 19-3: 203-228.

Brône, Geert, Kurt Feyaerts and Tony Veale (eds.) 2015 Cognitive Linguistics and Humor Research. Berlin: Mouton de Gruyter.

Brône, Geert and Bert Oben 2013 Resonating humor: a corpus-based approach to creative parallelism in discourse. In: Tony Veale, Kurt Feyaerts and Charles Forceville (eds.), Creativity and the Agile Mind: A Multidisciplinary Approach to a Multifaceted Phenomenon, 181-203. Berlin: Mouton de Gruyter.

Clark, Herbert H. 1996 Using Language. Cambridge/New York: Cambridge University Press.

Coulson, Seana 2000 Semantic Leaps. Frame-Shifting and Conceptual Blending in Meaning Construction. Cambridge: Cambridge University Press.

Coulson, Seana 2005 Sarcasm and the Space Structuring Model. In: Seana Coulson and Barbara Lewandowska-Tomaszczyk (eds.), The Literal and the Nonliteral in Language and Thought, 129-144. Berlin: Peter Lang.

Coulson, Seana $\quad 2015$ Frame-shifting and frame semantics: Joke comprehension on the space structuring model. In: Geert Brône, Kurt Feyaerts and Tony Veale (eds.), Cognitive Linguistics and Humor Research, 167-190. Berlin: Mouton de Gruyter.

Coulson, Seana and Marta Kutas 1998 Frame-shifting and sentential integration. UCSD Cognitive Science Technical Report 98-03.

Coulson, Seana and Marta Kutas 2001 Getting it: Human event-related brain response to jokes in good and poor comprehenders. Neuroscience Letters 316: 71-74.

Coulson, Seana and Todd Oakley 2003 Metonymy and conceptual blending. In: Klaus-Uwe Panther and Linda Thornburg (eds.), Metonymy and Pragmatic Inferencing, 51-79.

Amsterdam/Philadelphia: John Benjamins.

Coulson, Seana, Thomas P. Urbach and Marta Kutas2006 Looking back: Joke comprehension and the space structuring model. Humor. International Journal of Humor Research 19-3: 229250.

Fauconnier, Gilles 1994 Mental Spaces: Aspects of Meaning Construction in Natural Language. Cambridge (MA): MIT Press.

Fauconnier, Gilles 1997 Mappings in Thought and Language. Cambridge: Cambridge University Press. 
Fauconnier, Gilles and Turner, Mark 1998 Conceptual integration networks. Cognitive Science 22-2: 133-187.

Fauconnier, Gilles and Turner, Mark 2002 The Way We Think. Conceptual Blending and the Mind's Hidden Complexities. New York: Basic Books.

Feyaerts, Kurt and Geert Brône 2005 Expressivity and metonymic inferencing: stylistic variation in non-literary language use. Style 39-1: 12-36.

Feyaerts, Kurt and Bert Oben 2014 Tracing down schadenfreude in spontaneous interaction. Evidence from corpus linguistics. In: van Dijk W., Ouwerkerk J. (eds.), Schadenfreude:

Understanding Pleasure at the Misfortune of Others, 275-291. Cambridge UK: Cambridge University Press.

Feyaerts, Kurt, Geert Brône and Bert Oben In press Recontextualising Cognitive Linguistics: Multimodality in interaction. In: Barbara Dancygier (ed.), Handbook of Cognitive Linguistics. Cambridge: Cambridge University Press.

Fillmore, Charles 1982 Frame semantics. In: The Linguistic Society of Korea (ed.), Linguistics in the Morning Calm, 111-137. Seoul: Hanshin.

Fillmore, Charles 1985 Frames and the semantics of understanding'. Quaderni di Semantica 6-2: 222-254.

Gibbs, Raymond W. Jr. 1999 Speaking and thinking with metonymy. In: Klaus-Uwe Panther and Günter Radden (eds.), Metonymy in Language and Thought, 61-76.

Amsterdam/Philadelphia: John Benjamins.

Giora, Rachel 1991 On the cognitive aspects of the joke. Journal of Pragmatics 16-5: 465-486.

Giora, Rachel 1997 Understanding figurative and literal language: The graded salience hypothesis. Cognitive Linguistics 7: 183-206.

Giora, Rachel 2003 On our Mind: Salience, Context and Figurative Language. New York: Oxford University Press.

Giora, Rachel, Ofer Fein, Ann Kronrod, Idit Elnatan, Noa Shuval and Adi Zur 2004 Weapons of mass distraction: Optimal innovation and pleasure ratings. Metaphor and Symbol 19: 115-141.

Giora, Rachel, Ofer fein, Nurit Kotler and Noa Shuval 2015 Know hope: Metaphor, optimal innovation and pleasure. In Geert Brône, Kurt Feyaerts and Tony Veale (eds.), Cognitive Linguistics and Humor Research, 129-146. Berlin: Mouton de Gruyter.

Goldberg, Adele E. 1995 Constructions: A Construction Grammar Approach to Argument Structure. Chicago/London: The University of Chicago Press.

Hamrick, Phillip 2007 Notes on some cognitive mechanisms of humor. In: Diana Popa and Salvatore Attardo (eds.), New Approaches to the Linguistics of Humor, 140-150. Galatai: Editura Academica.

Hofstadter, Douglas and Gabora, Liane 1989 Synopsis of the workshop on humor and cognition. Humor. International Journal of Humor Research 2-4: 417-440.

Hünig, Wolfgang K. 2002 British and German Cartoons as Weapons in World War I. Invectives and Ideology of Political Cartoons, a Cognitive Linguistics Approach. Bern/Frankfurt a.M.: Peter Lang.

Koestler, Arthur 1964 The Act of Creation. London: Hutchison. 
Lakoff, George1987 Women, Fire and Dangerous Things. What Categories Reveal about the Mind. Chicago: Chicago University Press.

Lakoff, George and Mark Johnson 1980 Metaphors We Live By. Chicago: Chicago University Press.

Langacker, Ronald W. 1987 Foundations of Cognitive Grammar. Volume 1: Theoretical Prerequisites. Stanford (Ca.): Stanford University Press.

Langacker, Ronald W. 1993 Reference-point constructions. Cognitive Linguistics 4-1: 1-38.

Langacker, Ronald W. 2008 Cognitive Grammar. A Basic Introduction. New York: Oxford

University Press.

Lundmark, Carita 2005 Metaphor and Creativity in British Magazine Advertising. Luleå:

Luleå University of Technology.

Marín-Arrese, Juana 2003 Humour in language revisited: The view from cognitive linguistics. In: J.L. Camarés, C. Escobedo, D. García and N. Menéndez (eds.), El Humor en Todas las Épocas y Culturas. Oviedo: Universidad de Oviedo. CD.

Marín-Arrese, Juana 2006 Cognition and cultural in political cartoons. LAUD Papers in Linguistics 666. Duisburg: Universität Duisburg-Essen. $18 \mathrm{~S}$.

Mayerhofer, Bastian 2013 Perspective clashing as a humour mechanism. In Marta Dynel (ed.), Developments in Linguistic Humour Theory, 211-234. Amsterdam/Philadelphia: John Benjamins.

Michaelis, Laura A. 2005 Entity and event coercion in a symbolic theory of syntax. In: J.-O. Östman and M. Fried (eds.), Construction Grammar(s): Cognitive and Cross-Language Dimensions, 45-88. Amsterdam/Philadelphia: John Benjamins.

Müller, Ralph 2015 A metaphorical perspective on humour. In: Geert Brône, Kurt Feyaerts and Tony Veale (eds.), Humor and Cognitive Linguistics, 111-128. Berlin: Mouton de Gruyter.

Östman, Jan-Ola 2005 Construction Discourse: A prolegomenon. In: Jan-Ola Östman and Mirjam Fried (eds.), Construction Grammars. Cognitive Grounding and Theoretical Extensions, 121-144. Amsterdam/Philadelphia, PA: John Benjamins.

Panther, Klaus-Uwe and Linda Thornburg (eds.) 2003 Metonymy and Pragmatic Inferencing (Pragmatics and Beyond 113). Amsterdam/Philadelphia: John Benjamins.

Pollio, Howard R. 1996 Boundaries in humor and metaphor. In: Jeffrey S. Mio and Albert N. Katz (eds.), Metaphor: Implications and Applications. Mahwah, NJ: Lawrence Erlbaum, 231253.

Raskin, Victor 1985 Semantic Mechanisms of Humor. Dordrecht/Boston/ Lancaster: D. Reidel. Ritchie, Graeme 2006 Reinterpretation and viewpoints. Humor. International Journal of Humor Research 19-3: 251-270.

Tabacaru, Sabina and Maarten Lemmens 2014 Raised eyebrows as gestural triggers in humour: The case of sarcasm and hyper-understanding. European Journal of Humour Research 2-2, 11-31.

Tummer, José, Kris Heylen and Dirk Geeraerts 2005 Usage-based approaches in Cognitive Linguistics: A technical state of the art. Corpus Linguistics and Linguistic Theory 1-2, 225-261. 
Turner, Mark 2015 Blending in Language and Communication. In Ewa Dąbrowska and Dagmar Divjak (eds.), Handbook of Cognitive Linguistics, 211-232. Berlin: Mouton De Gruyter.

Vaid, Jyotsna, Rachel Hull, Roberto Heredia, David Gerkens and Francisco Martinez 2003 Getting a joke: The time course of meaning activation in verbal humor. Journal of Pragmatics 35: 1431-1449.

Veale, Tony 2004 Incongruity in humor. Root cause or epiphenomenon? Humor. International Journal of Humor Research 17-4: 419-428.

Veale, Tony 2012 Exploding the Creativity Myth. The Computational Foundations of Linguistic Creativity. Bloomsbury Academic.

Veale, Tony, Kurt Feyaerts and Geert Brône 2006 The cognitive mechanisms of adversarial humor. Humor. International Journal of Humor Research 19-3: 305-340.

Veale, Tony, Geert Brône and Kurt Feyaerts 2015 Humor as the killer-app of language. In: Geert Brône, Kurt Feyaerts and Tony Veale (eds.), Cognitive Linguistics and Humor Research, 112. Berlin: Mouton de Gruyter.

Veale, Tony, Kurt Feyaerts and Charles Forceville 2013 E unis pluribum. The art of creative duality in words, images and sounds. In: Tony Veale and Kurt Feyaerts (eds.), The Agile Mind. 